\title{
The National Ignition Facility Performance Status
}

C. Haynam, J. Auerbach, J.M. Di Nicola, S. Dixit, G. Heestand, M. Henesian, K. Jancaitis, K. Manes, C. Marshall, N. Mehta, M. Nostrand, C. Orth, R. Sacks, M. Shaw, S. Sutton, P. Wegner, W. Williams, C. Widmayer, R. White, S. Yang, B. Van Wonterghem

September 1, 2005

The National Ignition Performance Status Biarritz, France September 4, 2005 through September 9, 2005 
This document was prepared as an account of work sponsored by an agency of the United States Government. Neither the United States Government nor the University of California nor any of their employees, makes any warranty, express or implied, or assumes any legal liability or responsibility for the accuracy, completeness, or usefulness of any information, apparatus, product, or process disclosed, or represents that its use would not infringe privately owned rights. Reference herein to any specific commercial product, process, or service by trade name, trademark, manufacturer, or otherwise, does not necessarily constitute or imply its endorsement, recommendation, or favoring by the United States Government or the University of California. The views and opinions of authors expressed herein do not necessarily state or reflect those of the United States Government or the University of California, and shall not be used for advertising or product endorsement purposes. 


\title{
The National Ignition Facility Performance Status
}

\author{
Chris Haynam, Jerry Auerbach, Jean-Michel Di-Nicola, Sham Dixit, Glenn \\ Heestand, Mark Henesian, Ken Jancaitis, Ken Manes, Chris Marshall, \\ Naresh Mehta, Mike Nostrand, Charles Orth, Rick Sacks, Mike Shaw, Steve \\ Sutton, Paul Wegner, Wade Williams, Clay Widmayer, Ronald White, Steven \\ Yang, and Bruno Van Wonterghem
}

\author{
Lawrence Livermore National Laboratory, P.O. Box 808, Livermore, CA 94551, USA
}

\begin{abstract}
The National Ignition Facility (NIF) laser has been designed to support high energy density science (HEDS), including the demonstration of fusion ignition through Inertial Confinement. NIF operated a single "quad" of 4 beams from December 2002 through October 2004 in order to gain laser operations experience, support target experiments, and demonstrate laser performance consistent with NIF's design requirement. During this two-year period, over 400 Main Laser shots were delivered at $1 \omega$ to calorimeters for diagnostic calibration purposes, at $3 \omega$ to the Target Chamber, and at $1 \omega, 2 \omega$, and $3 \omega$ to the Precision Diagnostics System (PDS). The PDS includes its own independent single beam transport system, NIF design frequency conversion hardware and optics, and laser sampling optics that deliver light to a broad range of laser diagnostics. Highlights of NIF laser performance will be discussed including the results of high energy $2 \omega$ and $3 \omega$ experiments, the use of multiple focal spot beam conditioning techniques, the reproducibility of laser performance on multiple shots, the generation on a single beam of a $3 \omega$ temporally shaped ignition pulse at full energy and power, and recent results on full bundle ( 8 beamline) performance. NIF's first quad laser performance meets or exceeds NIF's design requirements.
\end{abstract}

\section{Introduction}

The National Ignition Facility (NIF) is designed to deliver 192 lasers beams, with carefully controlled energy, temporal, wavefront, and timing requirements, to a set of precisely positioned targets located near the center of a ten meter diameter target chamber. The extreme temperatures and pressures created by this array of lasers will be used to perform inertial confinement fusion and high energy density experiments. This facility is now being commissioned at the Lawrence Livermore National Laboratory, and upon scheduled completion in 2009, the NIF will be capable of delivering up to $1.8 \mathrm{MJ}$ of $3 \omega(351 \mathrm{~nm})$ energy. Pulse lengths will be adjustable between 0.2 and $32 \mathrm{~ns}$. The design of NIF is the culmination of over 25 years of laser development and operation, and is designed to exceed the energy of currently operating Nd:Glass lasers by a factor of 50. NIF's 192 beamlines are divided into 24 bundles, with 8 beamlines per bundle that are spatially arranged in a rectangular array with two beams wide by four beams high $(2 \mathrm{x} 4)$. A bundle is further divided into an upper and lower quad, each with 4 beamlines $(2 \times 2)$.

In April 2001, the NIF project began an effort titled NIF Early Light (NEL) to install and commission the first four beamlines, or first Quad, of the NIF. The location of these lasers is shown in Fig. 1. This first quad was operated through October 2004. The integrated operations demonstrated prototype and first article diagnostics and control systems, as well as a full cluster of beampath infrastructure, support systems, and utilities in the laser bay and switchyard. 


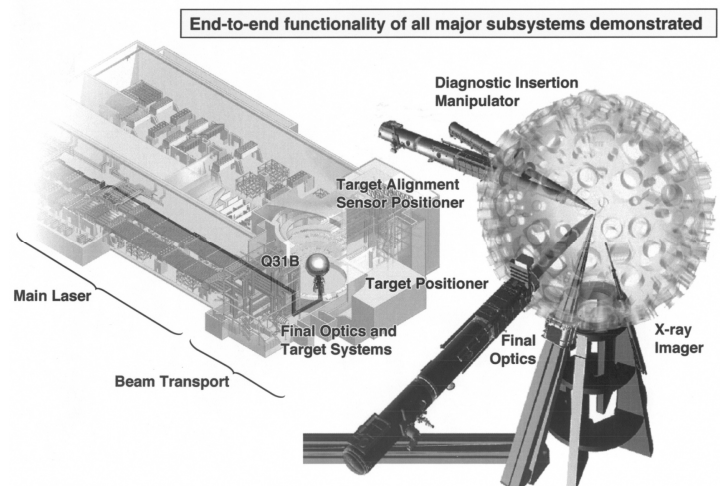

Figure 1. NIF Early Light (NEL) utilized four beamlines, with light originating with a nanojoule level pulse in the Master Oscillator Room (MOR) and amplified to the Joule level in the Injection Laser System (ILS), to the tens of kJ level in the main laser, and finally directed to the Final Optics System (FOS). The FOS uses two crystals, a $14 \mathrm{~mm}$ KDP second harmonic generation (SHG) crystal and $10 \mathrm{~mm}$ dKDP third harmonic generation (THG) crystal configured for Type I-Type II harmonic generation. A $7.7 \mathrm{~m}$ wedged focus lens is used to separate the three wavelengths in the chamber and form the focus of the $3 \mathrm{w}$ laser within $+50 \mathrm{~mm}$ of the target chamber center (TCC) A target positioner is used to position various targets to within an accuracy of tens of microns at this location.

In just under two years of operations, over 400 system shots were taken. A list of the major shot campaigns taken during this period is shown in Fig. 2. Shots to operationally qualify the $1 \omega$ main laser were completed late in 2002. Operational qualification of the $3 \omega$ FOS was completed early in 2003. The sequence of qualification activities involved have been documented elsewhere [1]. After operational qualification of the $1 \omega$ and $3 \omega$ sections was complete, a number of performance campaigns were conducted to characterize NIF energetics and beam quality. This paper will focus on the highlights of these performance campaigns. In addition to these performance campaigns, several NEL campaigns supported target physics experiments. Results of two initial experiments have been published, the first measuring long scale length laser plasma interactions and a second to study the 3D Hydrodynamics of Jets at high mach numbers [2],[3].
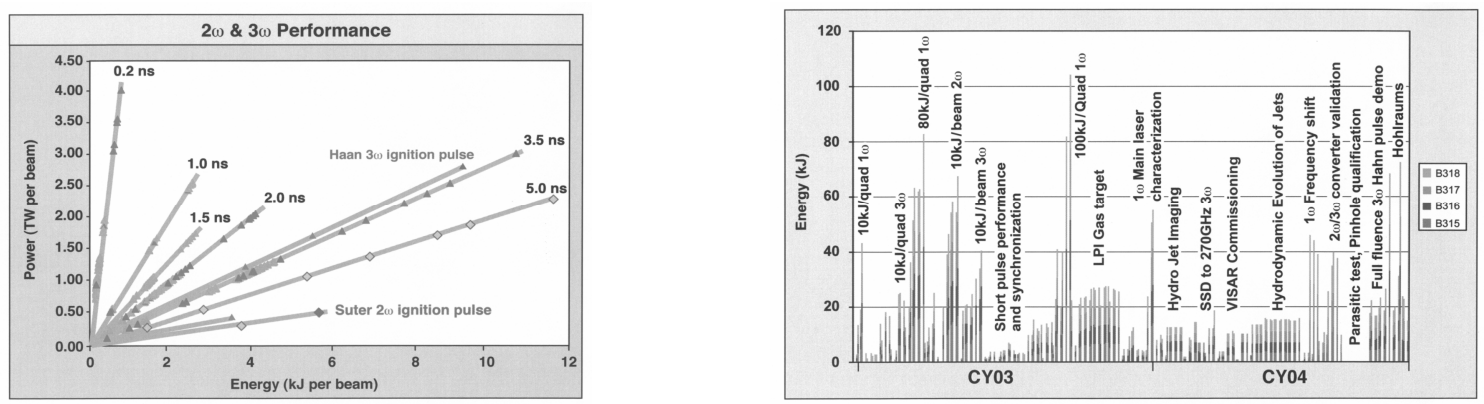

Figure 2. Over 400 system shots have been taken on NIF's first four beamlines. NIF has demonstrated $2 \omega$ and $3 \omega$ performance over much of its operational range. Triangles indicate $3 \omega$ shots and diamonds indicate $2 \omega$ shots.

These performance campaigns have also served to demonstrate much of NIF's operation space in terms of both power and energy. The plot of power vs. energy in Fig.2 shows a series of constant pulse duration shots as straight lines. All series are square pulses with the duration as labeled, with the exception of the $3 \omega$ shaped Haan ignition pulse and the $2 \omega$ shaped Suter ignition pulse. Two series (5ns and Suter) were accomplished with a single beamline delivered to our Precision Diagnostic System (PDS). The $2 \omega$ shots were accomplished by removing the THG and using a single $11 \mathrm{~mm}$ 
thick SHG crystal. Optimized $2 \omega$ operations are planned for 2006 with an $18 \mathrm{~mm} \mathrm{SHG} \mathrm{crystal.} \mathrm{This}$ performance map demonstrates the versatility of the NIF laser.

The energetics of each NIF beamline vary due to slight differences in beamline gain and transmission. In order to achieve precisely specified energies over a wide range of temporal shapes and pulse lengths, a computation model has been developed and utilized on every NIF shot. This Laser Performance Operations Model (LPOM) maintains a description of each beamline (i.e. optical losses, gain variations, amplifier and frequency conversion configurations). LPOM includes a 4 dimensional (3 spatial and 1 temporal) laser model that calculates energy extraction by solving the Frantz-Nodvik equation, and propagates the laser using a diffractive optics FFT code [5]. The LPOM uses feedback from NIF's standard diagnostics to specify and optimize laser setup (Fig.3). The LPOM model calculates the pulse shape required in each of the 48 PAMs to achieve the desired $3 \omega$ pulse shape and provides this to the MOR. Similarly, it calculates and specifies the energy required to be injected into each of the beamlines. It also performs an equipment protection function, by confirming that the laser has been set up as specified by analyzing the low energy ILS shots taken prior to each system shot.

A precision diagnostic system (PDS) is available to further diagnose the laser. A roving mirror can be placed to intercept any B31 beam and direct it to a standard set of FOS optics (Fig.3). PDS measures the near and far fields, power, and energy both before $(1 \omega)$ and after $(1 \omega, 2 \omega$, and $3 \omega)$ frequency conversion. Streak cameras are available with $15 \mathrm{ps}$ rise times at all three wavelengths.
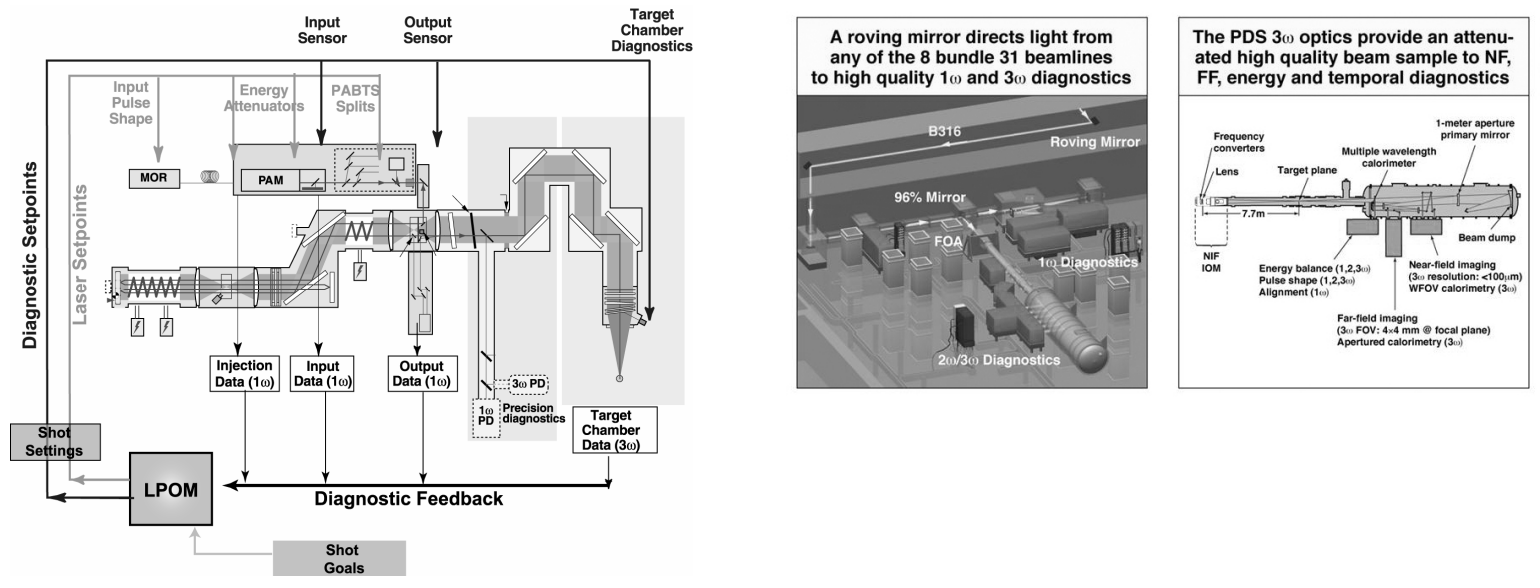

Figure 3. NIF standard diagnostics are shown on the left. The PDS diagnostic hardware is shown on the right
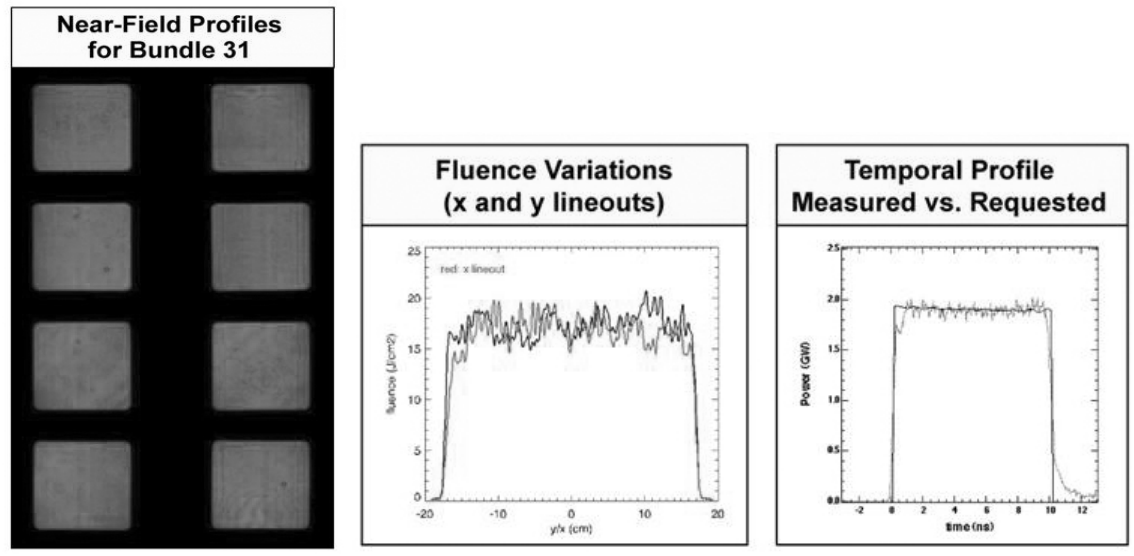

Figure 4. NIF has generated $152 \mathrm{~kJ}$ of $1 \omega$ light in a $10 \mathrm{~ns}$ flat in time pulse with excellent fluence uniformity. 


\subsection{Full bundle (8 beamline) recent results}

Starting in October 2004, NIF initiated the installation of the remaining optics into the NIF beampath, an activity that is scheduled for completion in 2009. In August of 2005 we completed the operational qualification of the first full 8 beamline bundle of NIF (Fig.4). We operated the full bundle with energies up to $152 \mathrm{~kJ}$ at $1 \omega$ using a $10 \mathrm{~ns}$ flat in time pulse. A single bundle of NIF ( $4 \%$ of the full system) exceeds the demonstrated $1 \omega$ drive energy of any presently operating fusion class laser.

\section{NIF Laser Performance and Repeatability}

The NEL 400-shot series demonstrated the performance level goals set for the ignition campaigns planned to start in 2010. Energies per beamline have exceeded goals with $26 \mathrm{~kJ}$ demonstrated at $1 \omega$, $11.4 \mathrm{~kJ}$ at $2 \omega$, and $10.4 \mathrm{~kJ}$ at $3 \omega$ (Full NIF equivalents of $5 \mathrm{MJ}, 2.2 \mathrm{MJ}$, and $2 \mathrm{MJ}$ respectively). Near field beam uniformity is shown in Fig.5, with the standard deviation of the normalized fluence
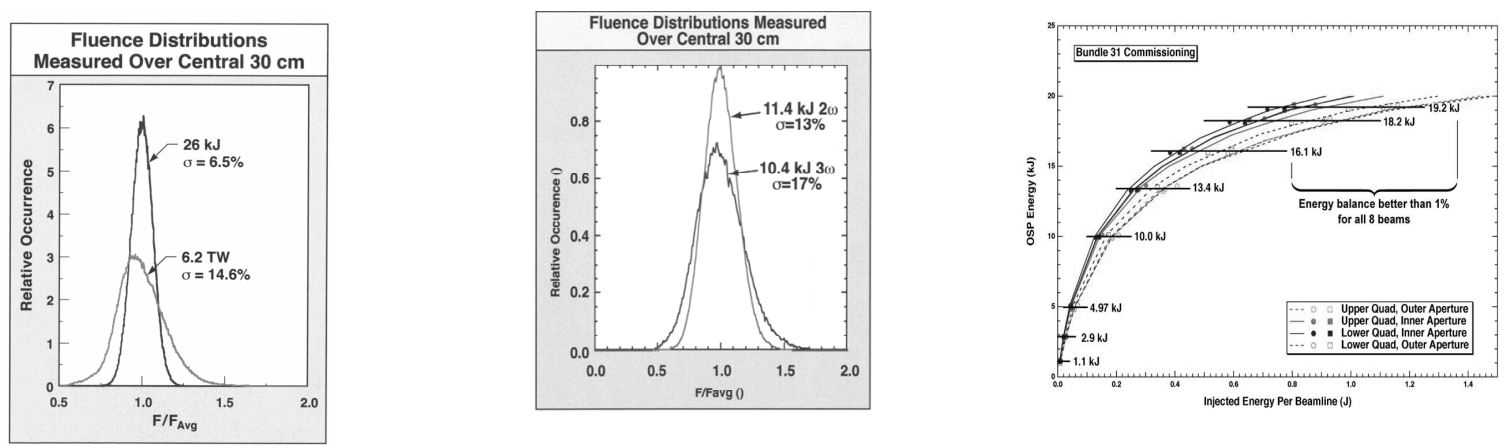

Figure 5. Fluence distributions for $1 \omega$ shots (left), $2 \omega$ and $3 \omega$ shots (center). $1 \omega$ output beamline energies are plotted against injected energies (right). Results show variations in gains between inner and outer apertures.

distribution varying from $6.5 \%$ at $1 \omega$ to $17 \%$ at $3 \omega$. Also shown are the recent 8 beamline results for a series of increasing energy $1 \mathrm{w}$ shots used to commission Bundle 31 and calibrate LPOM. Using the lower energy shots for calibration, the LPOM balanced the high energy shots to within $1 \%$, significantly exceeding the 3\% energy balance goal. The LPOM model has automated NIF's ability to achieve a broad variety of pulse shapes. As and example for a flat pulse the LPOM specified the highly shaped pulse at the oscillator as shown in Fig.6. Saturation in PAM and the main laser result in a flat in time output into the Final optics. Pulse shapes after frequency conversion are shown for the $3 \omega$ and $2 \omega$ ignition pulses, and two shapes used in target experiments. The deviations between the measured shape and the goal were readily minimized, with a single iteration required to obtain a $3 \%$ RMS deviation in the $3 \omega$ ignition pulse shape.

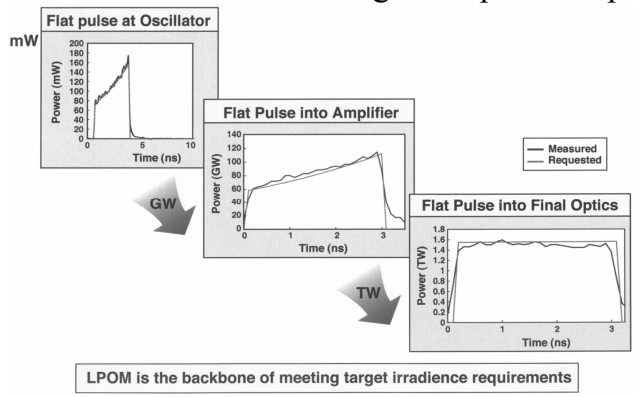

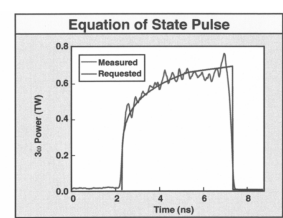
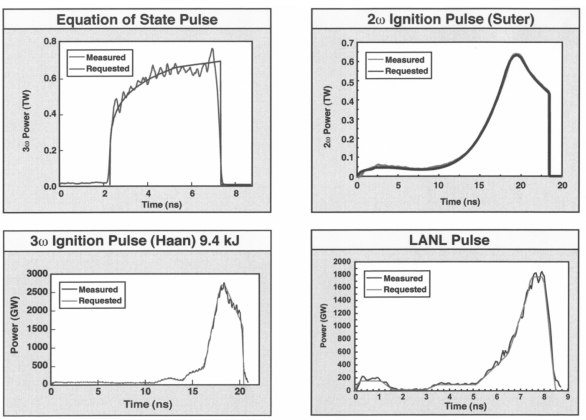

Figure 6. LPOM automates pulse shaping and shot setup. A wide range of pulse shapes have been produced. 
Target campaigns have been used to characterize the NIF laser. Laser quad synchronization was accomplished by arranging the focus of four 200 ps $200 \mathrm{~J} 3 \omega$ pulses in a line onto a Au coated silica disk. An x-ray streak camera (SXD) was used to record the relative pulse timing (Fig.7). The results from a first shot were used to adjust the mechanical length of a timing trombone in the PABTS, and a second shot to confirm the lasers were timed to within 6ps. The hydrodynamic jet campaign [2] required 17 identical energy shots. A histogram of a single beamline's energy in Fig.7 shows the energy repeatability is better than $2 \%$, well within the $3 \%$ energy balance allocation. The same hydro test demonstrated a pointing stability of $<50 \mu \mathrm{m}$ RMS. A single focal spot profile obtained from a PDS measurement is convoluted with the pointing variation observed during this test. Analysis indicates the FWHM of the 17 shot average FF spot increases only $1 \%$ relative that of single beam.
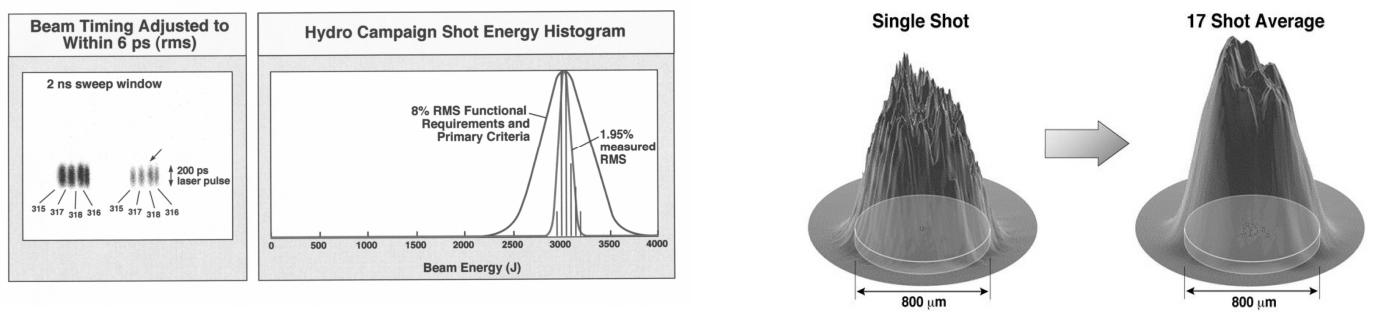

Figure 7. NIF energy repeatability and beam synchronization. NIF pointing requirement $(<50 \mu \mathrm{m}$ RMS $)$ was demonstrated in June 2004 Hydro Campaign. The single and average shot far field profiles are shown (left).

\section{Beam Conditioning on NIF}

Two of the three beam conditioning methods used on NIF are shown in Fig.8. Continuous phase plates (CPPs) are placed in the $1 \omega$ laser to create a controlled set of phase aberrations. The unconditioned NIF focal spot is about 200 microns at its 50\% enclosed energy diameter. By controlling the magnitude of these aberrations, focal spots have been created that varied in their full width at half maximum (FWHM) from between $250 \mu \mathrm{m}$ to $800 \mu \mathrm{m}$ at the center of the target chamber. Smoothing by spectral dispersion (SSD) has also been accomplished by phase modulating the NIF oscillator at $17 \mathrm{GHz}$ and angularly dispersing the beam during amplification with a grating located in the ILS. Bandwidths of up to $150 \mathrm{GHz}$ have been demonstrated at $1 \omega$ and up to $270 \mathrm{GHz}$ at $3 \omega$. The focal spot profile of six identical shots with an $800 \mu \mathrm{m}$ CPP were taken on the PDS diagnostic (Fig.8). The resulting encircled energy fractions for all six shots are coincident on this plot. This level of repeatability was valuable to analysis of NEL target experiments and will facilitate ignition experiments.
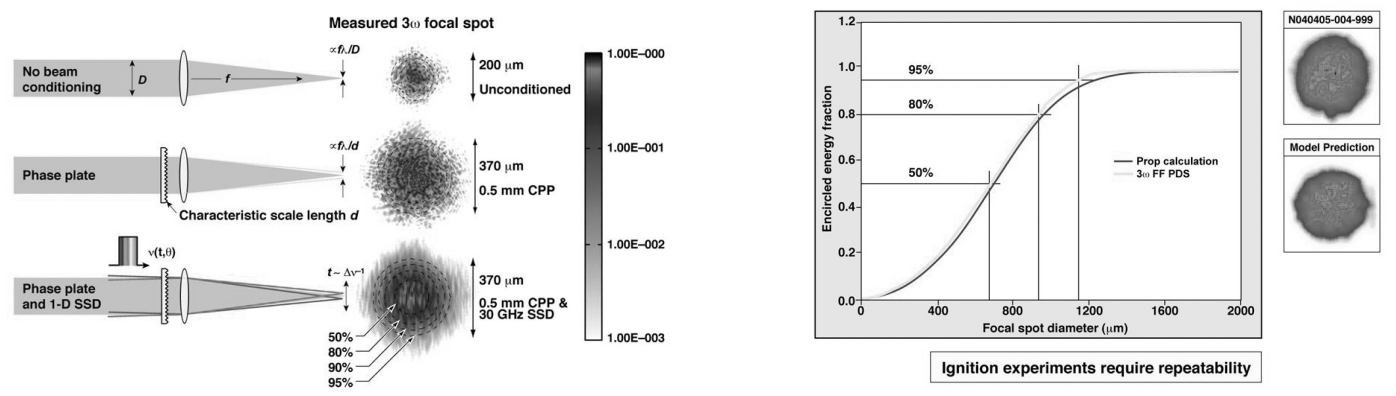

Figure 8. Beam conditioning is used to modify the spatial uniformity of the laser focal spot. Encircled energy fractions match model predictions and are nearly identical for 6 shots. 


\begin{tabular}{|c|c|c|c|c|c|c|}
\hline Campaign & Date & \begin{tabular}{|l|} 
Peak \\
Power \\
(TW)
\end{tabular} & $\begin{array}{c}\begin{array}{c}\mathrm{CPP} \\
\mu \mathrm{m} \\
(\mathrm{FWHM})\end{array} \\
\end{array}$ & $\begin{array}{c}\text { Polarization } \\
\text { on } \\
\text { Smoothing }\end{array}$ & $\underset{(\mathrm{GHz} 1 \omega)}{\mathrm{SSD}}$ & Location \\
\hline $\begin{array}{l}\text { Initial CPP, SSD } \\
\text { characterization }\end{array}$ & Aug-03 & 1.6 & 250 & - & & PDS \\
\hline VISAR commissioning & Apr-04 & 0.3 & 800 & - & - & TCC/PDS \\
\hline $\begin{array}{l}90 \mathrm{GHz} \text { SSD } \\
\text { demonstration }\end{array}$ & Apr-04 & 2.4 & - & - & 90 & PDS \\
\hline $\begin{array}{l}\text { Hydrodynamic } \\
\text { Evolution of Jets }\end{array}$ & Jun-04 & 2.0 & 800 & - & - & TCC/PDS \\
\hline $\begin{array}{l}\text { Full Power } 3 \omega \text { Ignition } \\
\text { (1.8MJ full NIF equivalent) }\end{array}$ & Sep-04 & 2.6 & - & Yes & - & PDS \\
\hline $\begin{array}{l}\text { High Temperature } \\
\text { Hohiraum }\end{array}$ & Oct-04 & 2.5 & 250 & Yes & - & TCC \\
\hline LPI - Gas Pipes & Sep-04 & 1.2 & 350 & Yes & 90 & TCC \\
\hline D1 Point design & Oct-10 & 2.3 & 1000 & Yes & 90 & - \\
\hline
\end{tabular}

\begin{tabular}{|c|c|c|c|}
\hline Specification & $\begin{array}{c}\text { Beamline } \\
\text { Requirement }\end{array}$ & $\begin{array}{l}\text { Measured 3w } \\
\text { Performance }\end{array}$ & \begin{tabular}{|c} 
Current \\
Beamline Status \\
\end{tabular} \\
\hline Pulse energy & $9.375 \mathrm{KJ}$ & $10.4 \mathrm{KJ}$ & \\
\hline Peak power & $2.6 \mathrm{TW}$ & $2.6 \mathrm{TW}$ (Haan) & \\
\hline Focal spot size & $600 \mu \mathrm{m}$ & $\begin{array}{l}600 \text { um ( } 80 \% \text { energy } \\
\text { enclosed in < 275um) }\end{array}$ & \\
\hline Temporal pulse dynamic & $250: 1$ & $>100: 1$ & \\
\hline Temporal shape & Output Haan Pulse & Output Haan Pulse & $\checkmark$ \\
\hline $\begin{array}{l}\text { RMS deviation in power } \\
\text { between beams }\end{array}$ & $\begin{array}{l}\leq 8 \% \text { RMS deviation } \\
\text { from specified power } \\
\text { averaged over } 2 \mathrm{~ns}\end{array}$ & $\begin{array}{l}\text { Components consistent with } \\
\text { requirement (energy balance } \\
\text { and repeatability, 3w temporal } \\
\text { shape, beam synchronization, } \\
\text { PAM stability, diagnostic } \\
\text { accuracy/repeatability) }\end{array}$ & \\
\hline Pulse length & $21 \mathrm{~ns}$ & $21 \mathrm{~ns}$ & $\checkmark$ \\
\hline RMS focal spot position & $\leq 50 \mu \mathrm{m} \mathrm{RMS}$ & $\leq 50 \mu \mathrm{m}$ RMS & 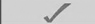 \\
\hline Prepulse & $<10^{8} \mathrm{~W} / \mathrm{cm}^{2}$ (96 beams) & $\begin{array}{l}\quad \ll 10^{8} \mathrm{~W} / \mathrm{cm}^{2} \text { (96 beams) } \\
\text { (PAM measurement, modeled } \\
\text { 10 gain and } 3 \text { (1) conversion) }\end{array}$ & \\
\hline Cycle time & $\begin{array}{l}\leq 8 \mathrm{~h} \text { between } \\
\text { full system shots }\end{array}$ & $s 3 \mathrm{~h}$ & \\
\hline
\end{tabular}

Figure 9. Beam conditioning demonstrations on NIF meet or exceed ignition requirements. NIF has demonstrated the performance levels required to support ignition experiment.

NIF's third beam conditioning technique, polarization smoothing, is described elsewhere in these proceedings [6]. A summary of NEL's beam conditioning campaigns is shown in Fig.9. These campaigns used the three techniques individually, or in combinations of two or all three as required to meet the objectives of target experiments or PDS tests.

\section{Summary}

The laser beam quality, alignment, timing, and pulse shaping requirements specified to achieve ignition are demanding. These specifications, shown in Fig.9 have all been demonstrated, on a beamline basis, during the NEL shot series. Commissioning results in 2005, demonstrating $150 \mathrm{~kJ} /$ bundle, continue to support our expectation that NIF's laser will support ignition tests in 2010.

\section{Acknowledgments}

We thank the NIF staff, particularly the operations and commissioning organization for reviewing test plans, providing practical recommendations, and working extended hours, and to the engineering team for designing custom mounts and diagnostics as requested to support the described measurements. Work performed under the auspices of the U.S. Department of Energy by the UC, Lawrence Livermore National Laboratory under Contract No. W-7405-ENG-48.

\section{References}

[1] B.M. Van Wonterghem, et al, "National Ignition Facility commissioning and performance, p.55, Proc. of SPIE Vol. 5314 San Jose, California (2004)

[2] Blue BE, et al, Experimental investigation of high mach number 3D hydrodynamic jets at the National Ignition Facility, PHYSICAL REVIEW LETTERS 94 (9): Art. No. 095005 MAR 112005.

[3] Glenzer SH, et al, Progress in long scale length laser-plasma interaction, NUCLEAR FUSION 44 (12): S185-S190 DEC 2004

[4] Paul J. Wegner, et al, "Characterization of Third-Harmonic Target Plane Irradiance on the National Ignition Facility Beamlet Demonstration Project, p.539, Proc. of the twelfth topical meeting on the technology of fusion energy, Volume 30, Number 3, Reno Nevada (1996)

[5] Shaw, M.J., Williams, W.H., House, R.K., Haynam, C.A., "Laser Performance Operations Model", Opt. Eng., Vol. 42, pp 2885-2873 (2004).

[6] S. Dixit, IFSA session $x x x x x x$ 